\title{
Mini-open lateral retro-pleural thoracic corpectomy for osteomyelitis
}

\author{
Amir Ahmadian, M.D. and Juan S. Uribe, M.D. \\ Department of Neurological Surgery, University of South Florida, Tampa, Florida
}

\begin{abstract}
Thoracic vertebral body corpectomy with associated deformity and neural element compression can be challenging. Multiple approaches have been proposed including trans-pedicular, costotransversectomy and trans-thoracic. Approach related pitfalls, nuances, morbidity and complication profile differ with each technique. A mini-open retro-pleural approach provides great access to bony pathology and neural elements without the need to violate the thoracic cavity or chest-tube placement postoperatively. Here we present a 56-year-old male with progressive back pain and suspected osteomyelitis/discitis at T-9 \& T-10 who presented with progressive deformity and failure of empiric antibiotic treatment. He underwent a two-level lateral corpectomy. The technique and operative nuances to a lateral retro-pleural approach to thoracic corpectomy are presented. Important surgical concepts such as patient positioning, appropriate use of intraoperative fluoroscopy, regional anatomy, postoperative care and pitfalls are outlined. Emphasis is made on a true lateral approach, posterior rib resection, wide retro-pleural dissection and preservation of the parietal pleura as you descent on to the vertebral body. Identifying the correct plane of dissection, timely corpectomy, placement of expandable cage and correction of deformity are discussed. Water-tight closure with removal of retro-pleural air utilizing an intra-operative water-seal technique using a red-rubber catheter is shown.
\end{abstract}

Nuvasive owns the copyright for figures included within the video and has given JNSPG permission to use them.

The video can be found here: http://youtu.be/17Xo_u3WHNg.

(http://thejns.org/doi/abs/10.3171/2013.V2.FOCUS13221)

$\begin{array}{lcccc}\text { KEY WORDS } & \bullet & \text { minimally invasive corpectomy } & \bullet & \text { thoracic corpectomy } \\ \text { osteomyelitis } & \bullet \quad \text { surgical anatomy } \quad \text { video } & \end{array}$

Manuscript submitted May 13, 2013.

Accepted June 11, 2013.

Please include this information when citing this paper: DOI: 10.3171/2013.V2.FOCUS13221.

Address correspondence to: Amir Ahmadian, M.D., University of South Florida, Neurosurgery, 2 Tampa General Circle, USF Health, 7th floor, Tampa, FL 33606. email: aahmadia@health.usf.edu. 